\begin{tabular}{|c|c|c|}
\hline & $\begin{array}{c}\text { GEOAMBIENTE ON-LINE } \\
\text { Revista Eletrônica do Curso de Geografia - UFG/REJ } \\
\text { Graduacăăo e Pós-Graduacăa em Geografia } \\
\text { http://revistas.ufg.br/index.php/geoambiente/index } \\
\text { Apoio: PRPG/PROAPUPEC } \\
\text { Jataí-GO | n.26 | Jan-Jun/2016 }\end{array}$ & $\begin{array}{l}\text { :GEO } \\
\text { ISSN } 1679-9860\end{array}$ \\
\hline
\end{tabular}

\title{
DIAGNÓSTICO E ESPACIALIZAÇÃO DO RISCO AMBIENTAL APLICADO AO MANEJO DO LIXO DOMÉSTICO EM
}

\section{ITUIUTABA-MG}

Nelio Paulo Sartini Dutra Júnior ${ }^{\mathbf{1}}$, Renata Vieira Souza ${ }^{2}$

(1 - Universidade Federal de Uberlândia - UFU, Faculdade de Ciências Integradas do Pontal FACIP, Programa de Pós-Graduação em Geografia do Pontal (PPGEP/FACIP/UFU), Rua 20, $\mathrm{n}^{\circ}$ 1600, CEP 38304-402 Bairro Tupã, Ituiutaba, MG, Brasil. Email: neliojunior28@gmail.com. 2 - Universidade Federal de Uberlândia (UFU), Faculdade de Ciências Integradas do Pontal (FACIP), Programa de Pós-Graduação em Geografia do Pontal (PPGEP/FACIP/UFU), Rua 20, nº 1600, CEP 38304-402 Bairro Tupã, Ituiutaba, MG, Brasil. Email: rennata00@ hotmail.com)

RESUMO: Com o crescimento das cidades, a produção de lixo não apenas aumentou como o seu próprio descarte e tratamento passaram a ser temáticas relevantes no âmbito das discussões ambientais, tendo em vista o volume da produção e as consequências ambientais do seu manejo incorreto. Este estudo tem como objetivo diagnosticar as áreas de riscos ambientais aplicado ao descarte incorreto do lixo doméstico em Ituiutaba-MG. Os procedimentos metodológicos basearam-se em coleta e mapeamento de dados do Censo Demográfico 2010 do Instituto Brasileiro de Geografia e Estatística, referente aos destinos de lixo domiciliar. O mapa de "Risco Ambiental aplicado ao manejo do lixo doméstico" foi criado com base na média simples dos dados anteriores citados. E a interpretação dos dados foi feita fundamentada em trabalho de campo e vivência dos pesquisadores. Conclui-se que em Ituiutaba-MG, as áreas de riscos ambientais de modo geral, corresponde ao perímetro periurbano. Diagnosticou-se que a população desta cidade está exposta a vários riscos ambientais de graves impactos, e muitas vezes ela é incapaz de responder corretamente a eles.

Palavras-chave: Risco Ambiental; Lixo Doméstico; Ituiutaba-MG.

\section{DIAGNOSIS AND SPATIAL DISTRIBUTION OF ENVIRONMENTAL RISK} APPLIED TO THE MANAGEMENT OF DOMESTIC WASTE IN ITUIUTABA-MG

Artigo recebido para publicação em 28 de Fevereiro de 2016 Artigo aprovado para publicação em 29 de Junho de 2016 


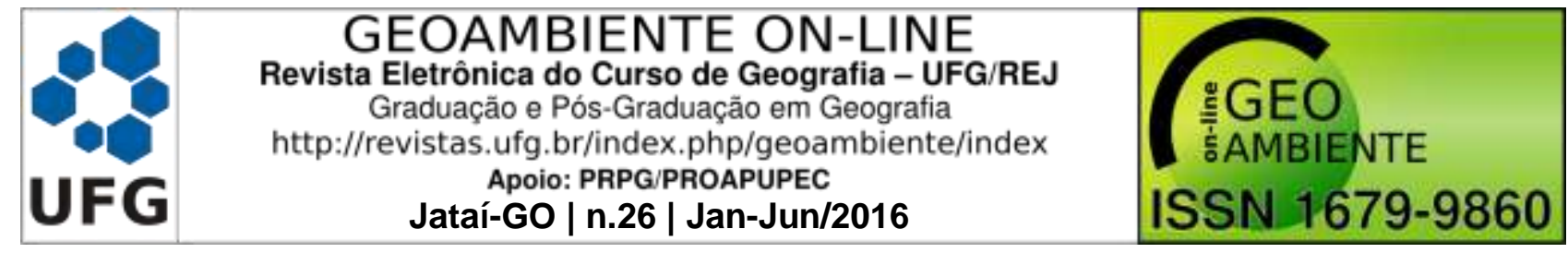

ABSTRACT: With the growth of cities, the waste production not only increased as his own disposal but treatment will be relevant issues in the context of environmental discussions, in view of the volume of production and the environmental consequences of their mismanagement. This study aims to diagnose the areas of environmental risks applied to the incorrect disposal of household waste in Ituiutaba-MG. The methodological procedures were based on the collection and data mapping according to the Census 2010 of the Brazilian Institute of Geography and Statistics, referring to domestic waste destinations. The map of "Environmental Risk applied to the management of household waste" was created based on the simple average of the previous data cited. And the interpretation of the data was done based on field research and by the experience of researchers. We conclude that in Ituiutaba$\mathrm{MG}$, the areas of environmental risks generally corresponds to the peri-urban perimeter. It was diagnosed that the population of this city is exposed to various environmental risks of serious impacts, and it is often unable to respond properly to them.

Key words: Environmental Risk; Domestic waste; Ituiutaba-MG.

\section{DIAGNÓSTICO Y ESPACIALIZACIÓN DEL RIESGO AMBIENTAL APLICADA A LA GESTIÓN LA BASURA DOMÉSTICA EN ITUIUTABA-MG}

Resumen: Con el crecimiento de las ciudades la producción de desechos, no solo aumentó, sino que su propio descarte y tratamiento pasaron a ser aspectos relevantes en el ámbito de las discusiones ambientales, respecto a volumen de producción y las consecuencias ambientales de su mal uso. Este estudio tiene como objetivo diagnosticar las áreas de riesgos ambientales aplicado al descarte incorrecto de basura doméstica en Ituiutaba-MG. Los procedimientos metodológicos se basaron en el registro y cartografía de los datos del Censo Demográfico 2010 del Instituto Brasileño de Geografía e Estadística, referente a los destinos de la basura domiciliar. El mapa de "Riesgo Ambiental Aplicado al manejo de basura doméstica" fue creado con base a la media simple de los datos anteriormente citados. En la interpretación de los datos fue realizada basada en el trabajo de campo y experiencia de los investigadores. Se concluye que en Ituiutaba-MG, las áreas de riesgo ambiental, de modo general, corresponden al perímetro periurbano. Se diagnosticó que los habitantes de esta ciudad están expuestos a varios riesgos ambientales de graves impactos, y muchas veces ellos son incapaces de responder correctamente a estos problemas.

Palabras clave: Riesgo ambiental; Basura doméstica; Ituiutaba-MG. 


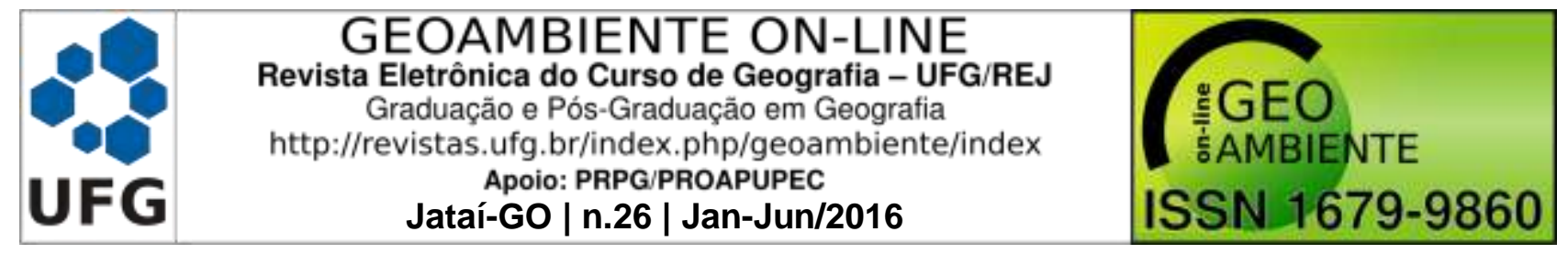

\section{INTRODUÇÃO}

Podemos associar o volume de resíduos (lixo) produzidos diariamente como um dos principais problemas que afetam a qualidade de vida da população urbana. Os resíduos dos mais variáveis possíveis, descartados pela população diariamente, constituem-se em um grande problema para a administração pública no que se refere à gestão e seu manejo adequado, já que este último está associado a custos elevados.

Com o crescimento das cidades, a produção de lixo não apenas aumentou como o seu próprio descarte e tratamento passaram a ser temáticas relevantes no âmbito das discussões ambientais, tendo em vista o volume da produção e as consequências ambientais do seu manejo incorreto.

Ituiutaba (Figura 1) está localizada na mesorregião do Triângulo Mineiro, no Estado de Minas Gerais, possui população estimada de mais de 102 mil habitantes, com área territorial de $2.598 .046 \mathrm{~km}^{2}$, e densidade demográfica de 37,40 habitantes por $\mathrm{km}^{2}$ (IBGE, 2015). A coleta do lixo domiciliar de Ituiutaba está sobre a responsabilidade da Prefeitura, sendo recolhido por caminhão tipo "caçamba", e a coleta seletiva é realizada desde 2011 pelo Programa de Coleta Seletiva (Coopercicla).

Contudo, mesmo existindo ambos os tipos de coleta, ainda possuem bairros e ruas da cidade nos quais os lixos domiciliares são descartados em córregos, queimados, jogados em térreos baldios e ruas. Portanto, a realização de um diagnóstico acompanhado da espacialização do risco ambiental aplicado ao manejo do lixo doméstico na cidade de Ituiutaba-MG é de grande valia para o desenvolvimento de ações de gestão eficientes e que garantam o bem estar da população.

Este trabalho tem como objetivo geral diagnosticar as áreas de riscos ambientais aplicado ao descarte incorreto do lixo doméstico em Ituiutaba-MG. Como objetivos específicos, pretende-se identificar em mapas temáticos, os seguintes destinos de lixo domiciliar: lixo queimado na propriedade; lixo enterrado na propriedade; lixo jogado em terreno baldio ou logradouro; e lixo jogado em rios e seus possíveis danos ao meio ambiente. 


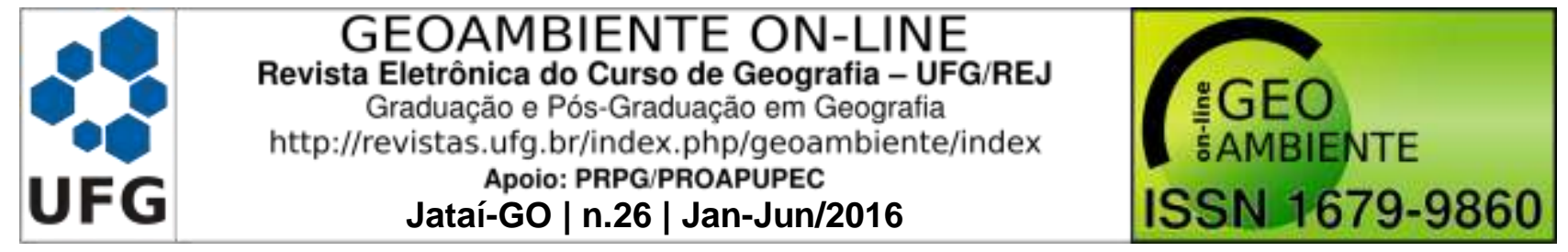

Figura 1 - Ituiutaba (MG): Localização do município e malha urbana (2015).
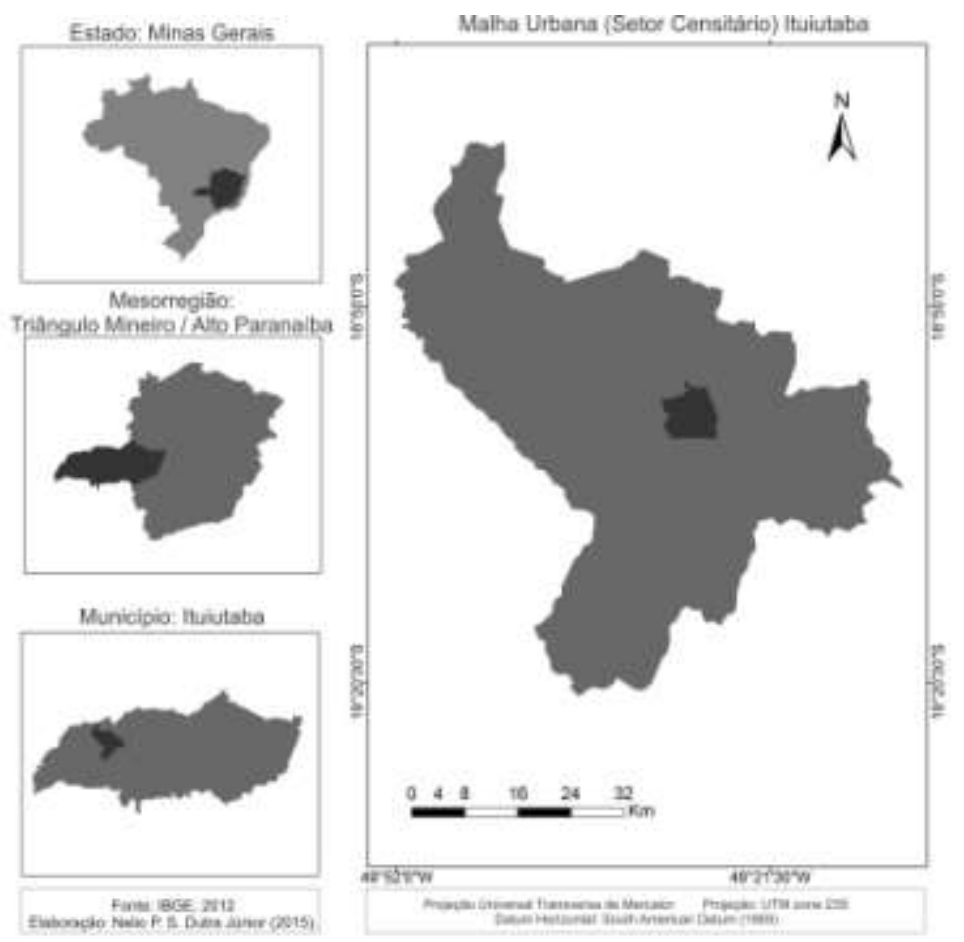

Fonte: IBGE, 2012. Elaboração: DUTRA JÚNIOR, 2015.

Os procedimentos metodológicos basearam-se em coleta e mapeamento de dados do Censo Demográfico 2010 do Instituto Brasileiro de Geografia e Estatística, referente aos destinos de lixo domiciliar. O mapa de "Risco Ambiental aplicado ao manejo do lixo doméstico" foi criado com base na média simples dos dados anteriores citados. E a interpretação dos dados foi feita com base em trabalho de campo e vivência dos pesquisadores.

\section{LIXO DOMÉSTICO E RISCO AMBIENTAL}

O alto grau de urbanização das cidades e, em muitas situações de maneira desordenada, associado ao modelo de desenvolvimento econômico predominante, com suas bases assentadas no consumismo, contribui com a produção acentuada de lixo. Titula-se de lixo tudo aquilo que não serve mais e é jogado fora.

Para a Associação Brasileira de Normas Técnicas (ABNT), lixo é definido como os restos das atividades humanas, consideradas pelos geradores como inúteis, indesejáveis ou descartáveis. Segundo Pereira (1991), o lixo pode ser classificado quanto ao seu estado físico (sólido, líquido e gasoso) e também quanto a sua origem (doméstico, industrial, comercial, 


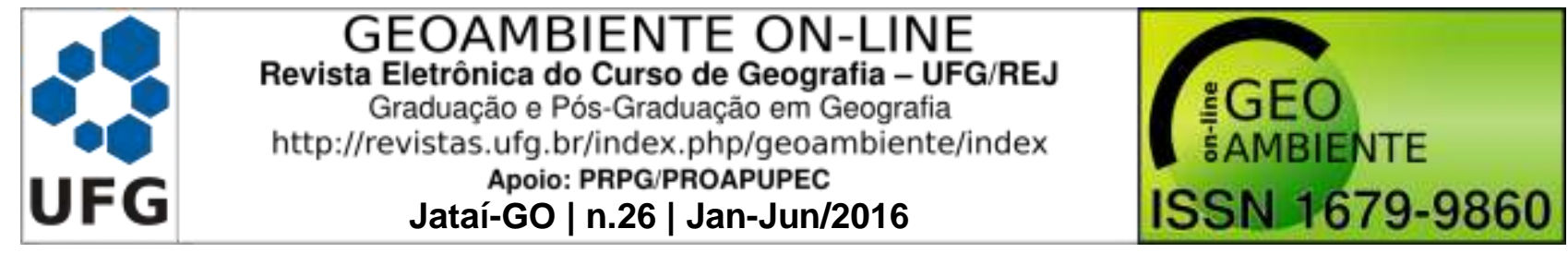

hospitalar, etc). Deve-se atentar para o lixo doméstico, subproduto do consumismo humano entranhado pelo modelo econômico capitalista vigente.

No espaço urbano a produção de lixo é inevitável devido à cultura do consumo. De acordo com o Instituto Brasileiro de Geografia e Estatística (IBGE, 2005), em cidades brasileiras, $76 \%$ dos resíduos sólidos residenciais, não recebem tratamento adequado, podendo ser facilmente observados acumulados em ruas, terrenos baldios, leitos de rios, valas, encostas de morros e outros locais impróprios. Sua disposição inadequada causa impactos graves ao solo, aos corpos hídricos, contribuindo ainda para a poluição do ar e consequentemente danos à população local, aos moradores da cidade em geral e, ao próprio espaço habitado.

É sabido que atualmente a maior parte da população brasileira habita ambientes urbanos, e, o inchaço das cidades associados ao desenvolvimento tecnológico e a cultura consumista das comunidades, têm colaborado para o aumento da produção de lixo e como consequência disso alterações negativas no ambiente. Compreende-se que as atividades cotidianas da comunidade urbana são reesposáveis pela contínua produção de lixo, portanto não é possível conceber uma cidade sem levar em conta a problemática gerada por ele. Ressalta-se dessa maneira, a criação de estratégias para gerar o mínimo de lixo possível e ainda políticas municipais de manejo adequado desse subproduto.

Na sociedade capitalista, se é que exista uma sociedade "não capitalista" visto que, do ponto de vista político, econômico e cultural a ideologia darwinista-capitalista prepondera, existe uma percepção crescente a respeito dos diversos riscos nos quais a sociedade sente-se vulnerável, sejam eles sociais e/ou ambientais. Para muitos, existe uma ideologia crédula na permanente existência de riscos, haja vista a organização social muitas vezes planejada para atender o capital. Gamba (2011, p.47) nos atenta para a naturalização dos riscos quando estes são oriundos do crescimento econômico, uma vez que comumente são percebidos como inevitáveis.

Do ponto de vista socioambiental, o crescimento das cidades principalmente depois de 1970 no Brasil, ocasionou uma (des) organização do espaço urbano em detrimento da acumulação de capital. Isso se deu (e obviamente permanece) com o aumento da população urbana em um curto período de tempo, tendo em vista que nos últimos 40 anos houve migração intensa da população rural para as cidades. Soma-se a isto o aumento das taxas de natalidade, da favelização e ocupação irregular de áreas de riscos, exploração intensa do meio natural, e aumento de resíduos de modo geral. 


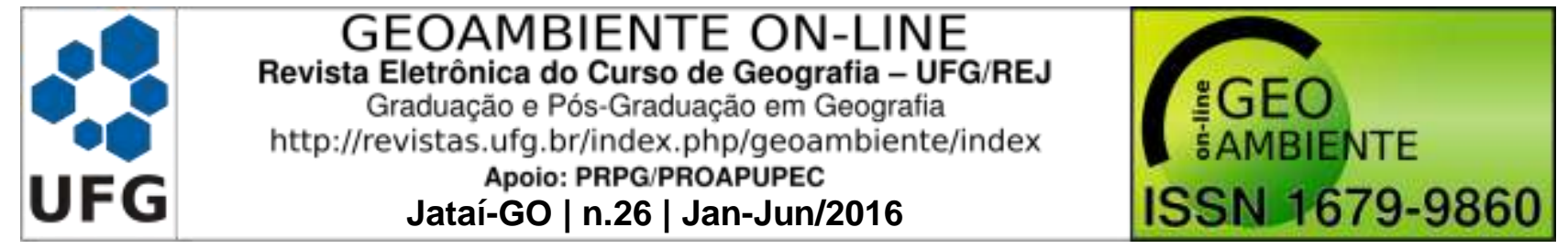

Evidentemente, é inegável que o aumento da população, e ainda da exploração ambiental, acarreta diariamente a produção de toneladas de lixos domésticos. Estes são descartados e depois coletados em caminhões de coleta (de lixo comum ou de coleta seletiva), ou podem ter destinos diferentes, podendo ser descartados em rios e/ou lagos, enterrados ou queimados nas propriedades, jogados em terrenos baldios ou logradouros, entre outros. Como resultados, o lixo recolhido e despejado em lixões, aterros sanitários, e aterros controlados vão, de várias formas, causar impactos no meio ambiente.

Do mesmo modo, e talvez de forma mais acentuada para a sociedade, o lixo não recolhido em propriedades oferecem aos moradores riscos socioambientais em razão da exposição e contato, permanente ou não, das pessoas com este subproduto. Gamba (2011) para criar um índice de vulnerabilidade socioambiental aplicada ao processo de escorregamento, tendo em vista as particularidades de seu objeto de estudo, utiliza um indicador a qual denomina de "índice de domicílios servidos por coleta de lixo". Combinando este último com o "índice de domicílios ligados à rede geral de esgoto ou pluvial" e "índice de domicílios com abastecimento de água da rede geral", a autora determina a "vulnerabilidade infraestrutural". O derradeiro, conjugado com o "índice de vulnerabilidade social" e "vulnerabilidade ambiental", decide o índice final já citado no início deste parágrafo.

A partir da análise de Gamba (2011), percebe-se que o fato de não existir coleta/serviço que recolha o lixo das residências é um fator influente na vulnerabilidade socioambiental. Na presente pesquisa, apoiando-se na autora supracitada, entende-se que nas residências onde o lixo e os resíduos de modo geral não são descartados de forma correta, existe eminentemente um risco ambiental aplicado ao manejo do lixo doméstico. Isso pode acarretar para a população diversos problemas ambientais, que variam de acordo com o destino final do lixo doméstico.

\section{RISCO SOCIOAMBIENTAL E LIXO DOMÉSTICO EM ITUIUTABA-MG}

Inicialmente, sabe-se que o lixo queimado em propriedades libera o gás carbônico (CO2) na atmosfera e contribui para a poluição do ar. De tal modo, é evidente que a "atmosfera é o meio de propagação dos poluentes emitidos e são os movimentos atmosféricos que determinam a frequência, a duração e a concentração dos poluentes a que estão expostos os receptores" (MOTTA; MENDES, 1995, p.166). Em consequência, locais cuja queima acontece de forma constante e ilegal, podem ocasionar aos moradores toxidades provenientes da alta concentração de dióxido de carbono no corpo humano. Os impactos mais comuns são 


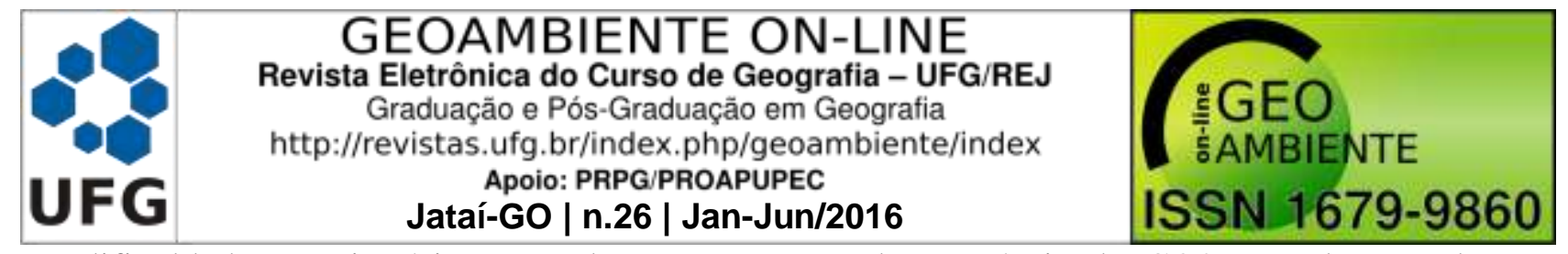

dificuldades respiratórias, em alguns casos quando os níveis de $\mathrm{CO} 2$ são altos, pode-se ocorrer sonolência, asfixia e até mesmo óbito.

De acordo com a (Figura 2), percebe-se que em Ituiutaba, os locais mais vulneráveis, ou seja, os mais susceptíveis a riscos oriundos da queima de lixo em propriedade, são as áreas periurbanas (vulnerabilidade alta), além dos bairros Satélite Andradina (59), Distrito Industrial M. A. Cancela (12) e o leste do bairro Independência (21) com vulnerabilidade muito alta. Estes bairros, historicamente, devido à distância do centro urbano, e o desinteresse do poder político e privado, resultam-se em locais com presença de moradias precárias, ruas sem asfaltamento, e lotes lindeiros.

Em relação ao lixo enterrado na propriedade (Figura 2), observa-se ao sul área com vulnerabilidade média, e ao norte área com vulnerabilidade muito alta. Todas elas possuem em suas proximidades nascentes de cursos de água, podendo contribuir não só para a poluição do nível freático com chorume e outros poluentes, mas, sobretudo com a poluição dos canais fluviais. Ao discutir as áreas de despejo de lixo, Sisinno e Moreira (1996, p.516) alerta para os riscos do uso de recursos hídricos comprometidos pela poluição:

[...] áreas de despejo não podem ser consideradas como o ponto final para muitas das substâncias contidas ou produzidas a partir do lixo urbano, pois, quando a água - principalmente das chuvas - percola através desses resíduos, várias dessas substâncias orgânicas e inorgânicas são carreadas pelo chorume: líquido poluente originado da decomposição do lixo. O chorume ou líquido percolado - cuja composição é muito variável - pode tanto escorrer e alcançar as coleções hídricas superficiais, como infiltrar no solo e atingir as águas subterrâneas, comprometendo sua qualidade e, por conseguinte, seu uso. (SISINNO; MOREIRA, 1996, p.516).

É relevante destacar que, quando a poluição chega ao nível freático, ela também atinge os cursos de água que são alimentados por essa água subterrânea. Assim, indiscutivelmente, as áreas onde o lixo é enterrado em propriedades, bem como os cursos de água de Ituiutaba, podem estar poluídas em razão dessa prática. Logo, a população está susceptível a diversos riscos ao consumir as águas sem tratamento adequado, seja para uso doméstico, para plantio e outros. 


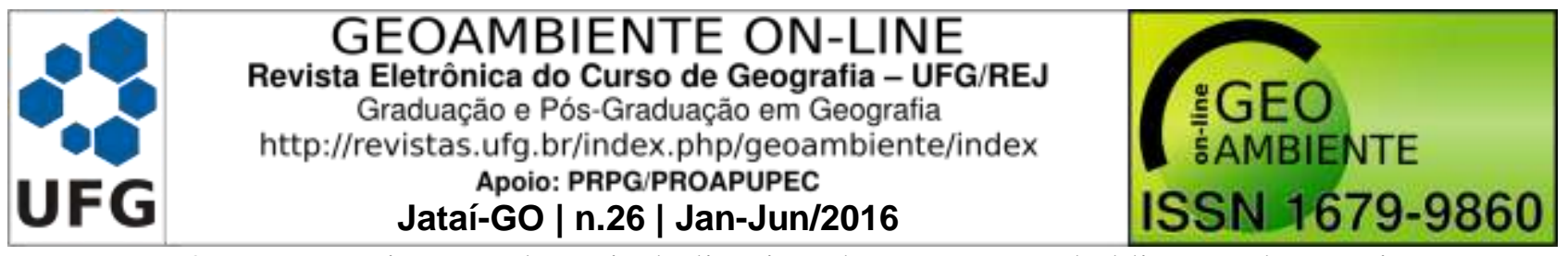

Os mesmos riscos podem vir do lixo jogado em terrenos baldios, tendo em vista que a água da chuva ao entrar em contato com esses resíduos permitem que os mesmos infiltrem no solo, podendo também chegar ao nível freático. No bairro Santa Maria (56) é maior a vulnerabilidade aplicada ao lixo jogado em terrenos baldios e logradouros, isso ocorre, pois nele, além de existirem um número proporcionalmente maior de terrenos baldios em relação às moradias, historicamente é um bairro com pouco investimento do Poder Público, seja em asfalto, rede de esgoto e água, e até mesmo coleta de lixo, pela dificuldade de acesso.

Figura 2 - Ituiutaba (MG): Riscos ambientais e destinos do lixo doméstico (2015)
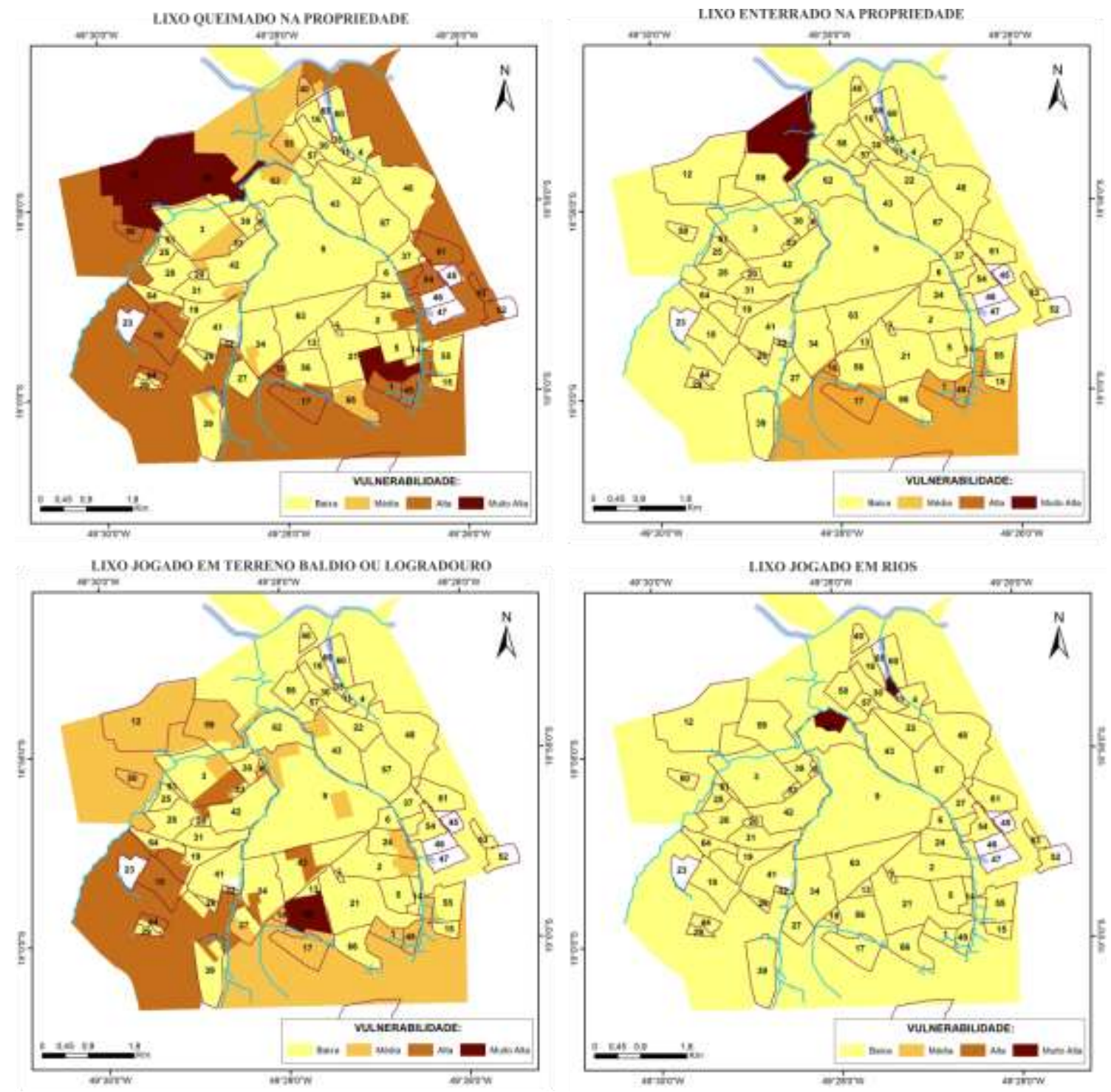

Fonte: IBGE, 2010. Elaboração: DUTRA JÚNIOR, 2015.

Pela observação da Figura 2, no campo "Lixo jogado em terreno baldio ou logradouro", vulnerabilidade alta em relação ao lixo jogado em logradouros ou terrenos 


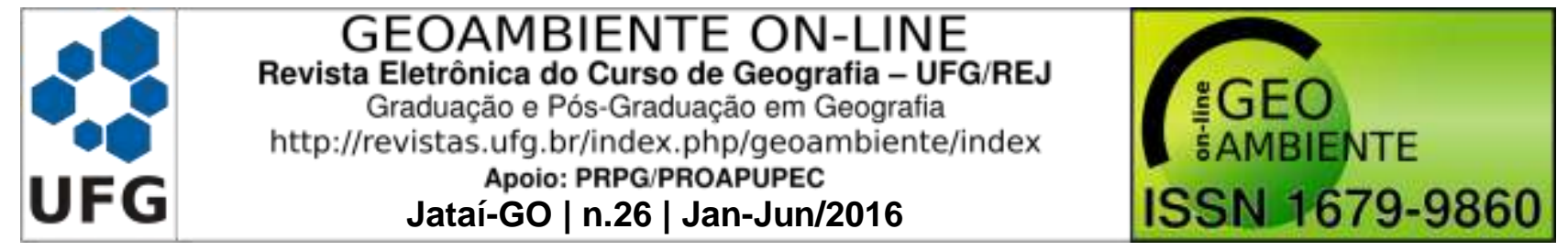

baldios na porção sudoeste de Ituiutaba. Destaca-se que além dela ser uma área afastada do centro urbano, nela está presente a BR-154, que embora não esteja pavimentada em sua maior parte, recebe fluxo constante de veículos, os quais comumente despejam lixo de diversos tipos nos limites entre a cidade e o campo. Embora nesta área a vulnerabilidade seja baixa em relação ao lixo jogados em rios, em contrapartida, a nordeste da malha urbana vê-se que nos bairros Setor Norte (62) e Nossa Senhora da Aparecida (35), esta prática além de ser presente, configura estes bairros como locais de vulnerabilidade muito alta aplicado ao lixo jogado em rios.

É de comum conhecimento que o lixo ao ser despejado em rios, lagos, e recursos hídricos de modo geral, poluem as águas que muitas vezes são usadas pela população, e em casos mais graves, contaminam completamente o recurso hídrico. Nos casos de contaminação por chumbo, por exemplo, nem todos os sistemas de tratamento de água conseguem monitorar estes contaminantes, e quando conseguem, não possuem tecnologias suficientes para filtrar corretamente a água para o uso da população. Ambos os cursos de água que estão sendo diretamente poluídos desaguam no Rio Tijuco, deste modo, ele está sendo poluído (e quem sabe contaminado) em um local que Ituiutaba não coleta água para uso direto, entretanto, logo a jusante, outras cidades usam a água deste rio. Observa-se que uma ação e/ou conjunto de práticas feitas em um município pode causar impactos socioambientais irreversíveis em outros municípios localizados à jusante do curso de água.

Em relação ao descarte incorreto do lixo doméstico em Ituiutaba, a Figura 3 apresenta uma síntese da vulnerabilidade da população a este impacto ambiental. É evidente que a população desta cidade está exposta a vários riscos ambientais de graves impactos, e muitas vezes ela é incapaz de responder corretamente a eles. Por isso, diz-se que ela é vulnerável a estes riscos. Nesta conjuntura, Alcântara (2012, p.37) deixa claro que nas análises de vulnerabilidade, deve-se considerar a incapacidade e a exposição ao risco:

Para análise da vulnerabilidade devem ser consideradas duas características: a exposição e a incapacidade. $\mathrm{Na}$ exposição são considerados os elementos que estão na área de risco, isto é, suscetíveis a algum dano, tais como, a população, as redes sociais, os bens e os serviços. Igualmente considera aqueles elementos oriundos da interface ser humano/natureza, que são agravados pelos perigos naturais, tais como, o desflorestamento, a degradação do solo, a mudança climática, etc. (ALCANTARA, 2012, p.37). 
GEOAMBIENTE ON-LINE

Revista Eletrônica do Curso de Geografia - UFG/REJ

Graduação e Pós-Graduaçăo em Geografia

http://revistas.ufg.br/index.php/geoambiente/index

Apoio: PRPG/PROAPUPEC

Jataí-GO | n.26 | Jan-Jun/2016

气 GEO

¿AMBIENTE

ISSN $1679-9860$

Figura 3 - Ituiutaba (MG): Risco Ambiental aplicado ao manejo do lixo doméstico (2010)

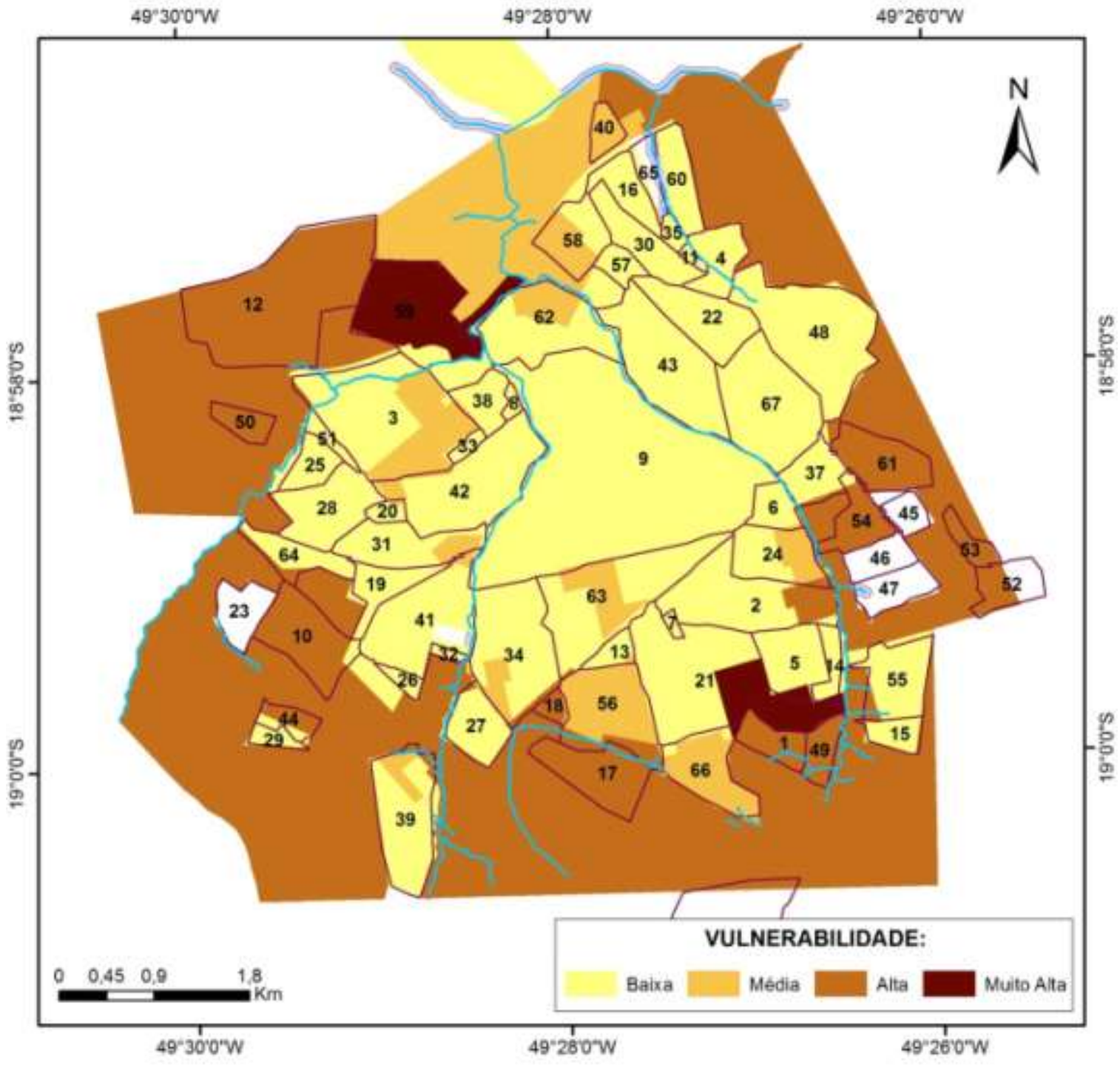

\begin{tabular}{|c|c|c|c|c|}
\hline \multicolumn{5}{|c|}{ BAIRROS: } \\
\hline 1. "Eairro sem identifcacha" & 14. Eldocado & 27. Jetónimo Mendonça & 40. Paranaiba & 53. Res Nadime Derze Jorge \\
\hline 2. Alcides Junqueira & 15. Esperança & 28. Lagoa Amill & 41. Pirapitinga & 54. Res Portal dos ipts \\
\hline 3. Alverada & 16. Gardbnia & 29. Lagoa Azul II & 42. Plabina & 55. Santa Edwiges \\
\hline 4. Bela Vista & 17. Gerson Baduy 1 & 30. Maria Vilela & 43. Progresso & 56. Santa Maria \\
\hline 5. Brasil & 18. Gerson Batuy if & 31, Marta Heiena & 44. Res Dr M B Ferreira & 57. Santo Antônio \\
\hline 6. Camargo & 19. Guimarses & 32. Minim & 45. Res Buntis & $\begin{array}{l}\text { 58. Săo José } \\
\text { 59. Satelite Andradina }\end{array}$ \\
\hline 7. Carvalho & 20. Helio & 33. Morada do Sol & 46. Res. Canas I & 60. Setor Ind. António Baduy \\
\hline 8. Central & 21. Independéncia & 34. Natai & 47. Res. Canas II & 61. Setor Leste \\
\hline 9. Centro & 22. Ipiranga & $35 \mathrm{~N}$. Sra da Aparecida & 48. Res. Drummond & 62. Setor Norte \\
\hline 10. Cidade Jardim & 23. Jardim Copacubana & 36. Nova ltuiutaba & 49. Res Gilca Vieia Cancela & 63. Setor Sul \\
\hline 11. Cristina & 24. Jardim do Rosario & 37. Novo Honzonte & 50. Res. Jardim Eurcpa II & 64. Sol Nascente \\
\hline 12. Dist Ind, M.A. Cancela & 25. Jardim Europa & 38, Novo Mundo & 51. Res. Monte Verde & 65. Tiradentes \\
\hline 13. Elandia & 26. Jardim Jamila & 30. Novo Tompo II & 52. Res. Nadime Derze II & $\begin{array}{l}\text { 66. Tupă } \\
\text { 67. Universitario }\end{array}$ \\
\hline
\end{tabular}

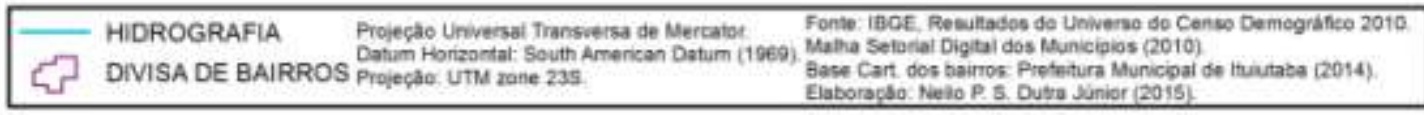

Fonte: IBGE, 2010. Elaboração: DUTRA JÚNIOR, 2015. 


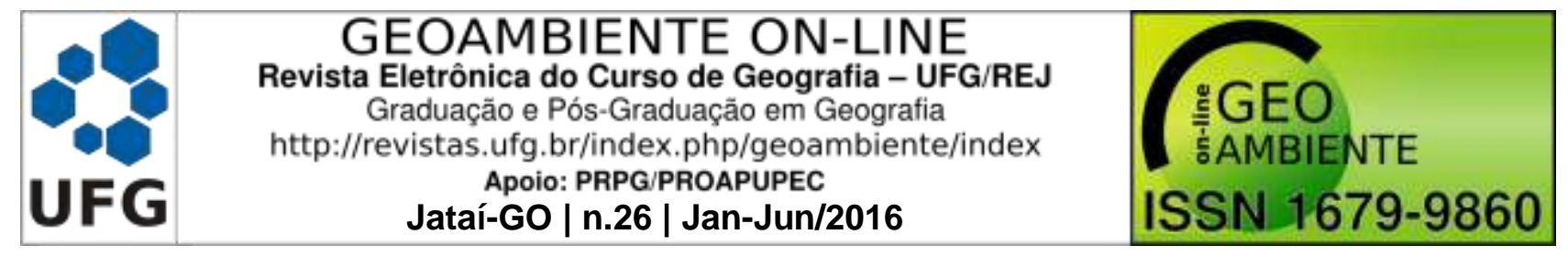

Assim, para entender a vulnerabilidade aplicada ao lixo doméstico, afirma-se que a população está exposta a estes riscos, e que o próprio risco aufere incapacidade de resposta do ser humano e da natureza, tendo em vista que os manejos ilegais e incorretos deste lixo impactam a todo o meio ambiente, incluindo fauna, flora, e população de modo geral.

Vê-se na Figura 3 que quase toda a área correspondente ao perímetro periurbano, um local que deveria ser de permanente proteção ambiental em razão da proximidade com o campo, está comprometida com vulnerabilidade alta aplicada ao risco ambiental de descarte de lixo. Nos bairros centrais encontram-se locais com vulnerabilidade média, algo alarmante levando em conta a densidade demográfica e o fluxo de pessoas que diariamente circulam nestes bairros.

Nos bairros Satélite Andradina (59) e porção leste do bairro Independência (21), foram encontrados os piores resultados, ou seja, vulnerabilidade muito alta. Para agravar a situação de risco, ambos estão localizados a menos de 50 metros de dois córregos urbanos, comprometendo não só a população que está exposta aos riscos oriundos do lixo doméstico, como ainda, o curso de água e todos que utilizam este recurso.

A partir dessa análise inicial dos resultados, é nítido que o descarte de lixo em Ituiutaba-MG precisa não apenas ser discutido, mas planejado. Como proposta mitigadora, inicialmente acredita-se que deve haver uma campanha de educação ambiental para a população das áreas com vulnerabilidade muito alta e alta. Nestas campanhas, é importante ressaltar os riscos que a comunidade está submetida em razão do manejo incorreto do lixo, e os impactos ambientais destas ações.

Deve-se também identificar as principais dificuldades da população em relação ao manejo do lixo, se ela possui alternativas para o descarte, e se essas alternativas estão adaptadas a situação e rotina do bairro. É imprescindível, igualmente, listar os problemas de ordem governamental, e identificar a responsabilidade do Poder Público frente a estes impactos ambientais.

E por fim, propor uma agenda com mudanças de postura, com objetivos a longo, médio e curso prazo, englobando a população, o poder local, e a iniciativa privada, baseandose os preceitos do desenvolvimento local sustentável. 


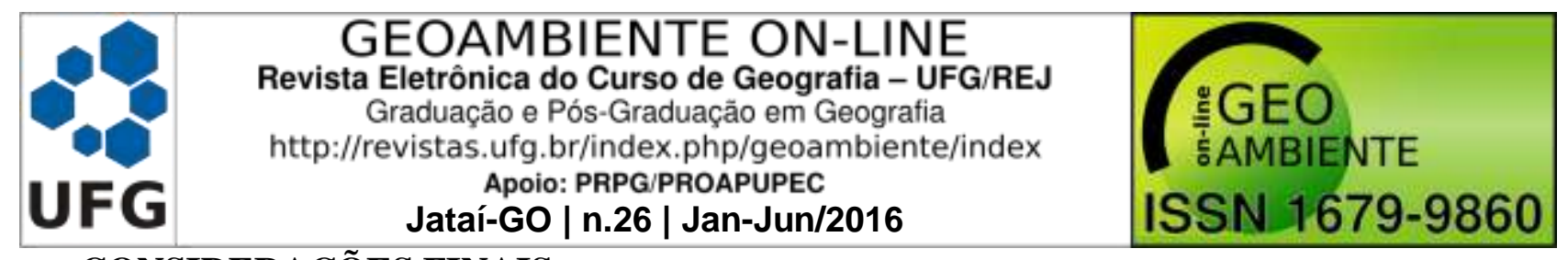

CONSIDERAÇÕES FINAIS

O crescimento populacional e a consequente expansão urbana, associados ao modelo consumista das comunidades contemporâneas têm contribuído cada dia mais para a produção de lixo. Somados a isso ainda temos o manejo inadequado desse subproduto, o qual evidentemente condiciona impactos ambientais graves, e, portanto prejuízos aos moradores da cidade em geral. Isso foi um dos pontos principais verificados neste estudo.

Afirma-se que a população de Ituiutaba está exposta a riscos, e de modo geral as áreas que correspondem ao perímetro periurbano, como demostrou o mapeamento feito, são as áreas que apresentaram os piores resultados. Entretanto, o mapeamento também apontou bairros centrais com vulnerabilidade média. Demostrando dessa forma a disposição dos riscos ambientais aplicados ao manejo do lixo doméstico em diferentes locais da cidade em estudo.

Os mapas temáticos nos revelou os diversos destinos do lixo domiciliar em ItuiutabaMG e suas possíveis consequências. O lixo queimado em propriedades libera o gás carbônico (CO2) na atmosfera e contribui para a poluição do ar. O lixo enterrado na propriedade em áreas próximas a nascentes de cursos de água podem contribuir não só para a poluição do nível freático com chorume e outros poluentes, mas, sobretudo com a poluição dos canais fluviais. O lixo jogado em terrenos baldios, em contato com a agua da chuva, permite que, resíduos tóxicos infiltrem no solo, podendo também chegar ao nível freático. O lixo jogado em rios pode contribuir para a poluição das suas águas que muitas vezes são usadas pela própria população.

De maneira geral, percebe-se que os problemas causados pelo manejo incorreto do lixo domiciliar na cidade de Ituiutaba-MG são diversos, e as propostas mitigadoras apontadas nos remete a meios e não a fins.Entretanto, parte da solução também exige que se faça uma reflexão acerca do modelo de sociedade que tem suas bases assentadas no consumismo, e no individualismo, acentuando cada vez mais a produção de bens de consumo e que vão ser logo dispensados na forma de lixo, que por sua vez devido ao seu descarte e manejo incorretos, ocasionam danos muitas vezes irreversíveis ao meio ambiente.

\section{REFERENCIAS BIBLIOGRÁFICAS}

ALCÂNTARA, V. da S. de. Vulnerabilidade socioambiental na macrorregião da Costa Verde. 2012. 128 f. Dissertação. Mestrado em Estudos Populacionais e Pesquisas Sociais. Escola Nacional de Ciências Estatísticas do Instituto Brasileiro de Geografia e Estatística, Rio de Janeiro. 2012. 


\begin{tabular}{|c|c|c|}
\hline & $\begin{array}{c}\text { GEOAMBIENTE ON-LINE } \\
\text { Revista Eletrônica do Curso de Geografia - UFG/REJ } \\
\text { Graduação e Pós-Graduaçăo em Geografia } \\
\text { http://revistas.ufg.br/index.php/geoambiente/index } \\
\text { Apoio: PRPG/PROAPUPEC } \\
\text { Jataí-GO | n.26 | Jan-Jun/2016 }\end{array}$ & $\begin{array}{l}\text { :GEO } \\
\text { ISSN } 1679-9860\end{array}$ \\
\hline
\end{tabular}

GAMBA, C. Avaliação da Vulnerabilidade Socioambiental dos Distritos do Município de

São Paulo ao Processo de Escorregamento. 2011. 204 f. Dissertação. Programa de Pós-

Graduação em Geografia Humana do Departamento de Geografia da Faculdade de Filosofia, Letras e Ciências Humanas. Universidade de São Paulo, São Paulo. 2011.

IBGE Cidades. Disponível: <http://www.cidades.ibge.gov.br/>. Acesso: 15 de jun. 2015.

Instituto Brasileiro de Geografia e Estatística, responsável pelo censo populacional no país. 2005. Disponível: <http://www.sober.org.br/palestra/6/832.pdf\%3E>. Acesso: 10 de jun. 2015.

MOTTA, R. S. da.; MENDES, A. P. F. Custos de saúde associados à poluição do ar no Brasil. Pesquisa e Planejamento Econômico. V.25, n.1, p.165-198, abr. 1995.

PEREIRA, N. S. 1991. Terra Planeta Poluído, 1. Sagra, Porto Alegre.

SISINNO, C. L. S.; MOREIRA, J. C. Avaliação da contaminação e poluição ambiental na área de influência do aterro controlado do Morro do Céu, Niterói, Brasil. Caderno de Saúde Pública. P. 515-523, out-dez, 1996. Disponível em: <http://www.scielo.br/pdf/csp/v12n4/0243.pdf>. Acesso: 16 jun. 2015. 